\title{
NOTAS SOBRE O SETOR SAÚDE E SANEAMENTO NO ORÇAMENTO PÚBLICO DO ESTADO DE SÃO PAULO PARA 1987
}

\author{
Evelin Naked de Castro Sá*
}

Expressão contábil que é do planejamento governamental e instrumento desse mesmo planejamento, o orçamento público do Estado de São Paulo apresenta, para 1987, alguns dados de interesse para os docentes e profissionais da área da Saúde, que comentamos a seguir.

(a) O ORÇAMENTO PÚBLICO PARA 1987, DO ESTADO DE SÃO PAULO, aprovado pela Lei n: 5403, de 04/12/1986, tem um total de Cz $\$ 138.066 .415 .735$ e está assim distribuído, por funções:

\begin{tabular}{lrr} 
Demonstração da despesa por funções & Cz\$1,00 & \multicolumn{1}{c}{$\%$} \\
Legislativa & 884.911 .821 & 0,67 \\
Judiciária & 12.023 .669 .418 & 9,10 \\
Administração e Planejamento & 38.537 .020 .606 & 29,16 \\
Agricultura & 1.895 .453 .391 & 1,43 \\
Comunicações & 193.655 & 0,01 \\
Defesa Nacional e Segurança & & \\
Pública & 10.168 .085 .805 & 7,70 \\
Desenvolvimento Regional & 464.655 .884 & 0,35 \\
Educação e Cultura & 30.535 .237 .744 & 23,11 \\
Energia e Recursos Minerais & 1.275 .324 .946 & 0,97 \\
Habitação e Urbanismo & 723.704 .544 & 0,55 \\
Indústria, Comércio e Serviços & 1.127 .783 .417 & 0,85 \\
Saúde e Saneamento & 8.563 .599 .598 & 6,48 \\
Trabalho & 168.815 .593 & 0,13 \\
Assistência e Previdência & 13.739 .423 .909 & 10,40 \\
Transporte & 8.420 .188 .804 & 6,37 \\
Reserva de Contingência & 3.600 .000 .000 & 2,72 \\
\cline { 2 - 2 } Total & & \\
\cline { 2 - 3 } & $132.128 .069 .135 * *$ & 100,00
\end{tabular}

(b) A função 13 - Saúde e Saneamento - está orçada em Cz\$ 8.563.599,598 e representa 6,48\% do orçamento, distribuída pelos seguintes programas:

\begin{tabular}{|c|c|c|}
\hline 07 - Administração & 3.840 .558 & 0,05 \\
\hline 54 - Recursos Hídricos & 142.384 .600 & 1,66 \\
\hline 59 - Regiões Metropolitanas & 100 & 0 \\
\hline 75 - Saúde & 7.885 .604 .880 & 92,08 \\
\hline 76 - Saneamento & 108.378 .260 & 1,27 \\
\hline 77 - Proteção ao Meio Ambiente & 423.391 .200 & 4,49 \\
\hline Total & 8.563 .599 .598 & 0,00 \\
\hline
\end{tabular}

Nota-se, assim, que embora tendo grande expressão

no setor, a Secretaria de Estado da Saúde não executa com exclusividade a função governamental "Saúde e Saneamento". São os seguintes órgãos com participação nessa função:

\section{Órgãos, Secretarias de Estado}

Secretaria da Saúde

Secretaria da Administração

Secretaria de Obras e

Saneamento

Secretaria de Estado do Governo Total

\begin{tabular}{|c|c|}
\hline $\mathrm{Cz} \$$ & $\%$ \\
\hline $6.045 .488: 991$ & 70,60 \\
\hline 328.581 .239 & 3,84 \\
\hline 674.154 .160 & 7,87 \\
\hline 1.515 .375 .208 & 17,69 \\
\hline 8.563 .599 .598 & 00,00 \\
\hline
\end{tabular}

A Secretaria de Estado da Saúde participa, ainda, da função Assistência e Previdência, com uma parcela de Cz\$ 31.244.070, totalizando Cz\$6.076.733.061 como orçamento próprio.

(c) Os campos de atuação dos órgãos acima citados, coparticipantes da função governamental, são os seguintes:

\section{Secretaria da Saúde}

- promover, presevar e recuperar a saúde da população;

- exercer a função de órgão normativo do Governo do Estado, no Setor Saúde;

- estudar, planejar, orientar, coordenar, supervisionar e executar, em todo o território do Estado, medidas visando à melhoria das condições sanitárias da população;

- estudar problemas de saúde pública, promovendo pesquisas científicas necessárias à sua solução;

- promover articulação com outros órgãos de saúde pública ou de assistência social estatal, paraestatal e privada, cuja atuação possa contribuir para a consecução das finalidades do órgão;

- executar o saneamento ambiental, visando à erradicação e o controle de doenças transmissíveis, bem como o combate a vetores;

- fabricar medicamentos e outros produtos de interesse da saúde pública, utilizando-se de matéria prima de síntese própria, de aquisição local, de importação e de extração ou de cultura de origem vegetal, animal ou mineral;

- fornecê-los aos órgãos de saúde pública e de assistência social do Estado, a outras entidades públicas, de previdência privada, ou particulares que

\footnotetext{
* Departamento de Prática de Saúde Pública da Faculdade de Saúde Pública da Universidade de São Paulo

- Av. Dr. Arnaldo, 715 - 01255 - São Paulo, SP - Brasil.

** só os recursos do Tesouro do Estado.
} 
prestem assistência médica à população, declaradas de utilidade pública;

- adquirir medicamentos de laboratórios produtores, com o objetivo de assegurar o seu fornecimento para as entidades referidas no ítem anterior;

- proporcionar treinamento a estudantes e técnicos especializados nas profissões relacionadas com as atividades da Pasta;

- realizar estudos, pesquisas e experiências em cancerologia, promover a formação de cancerologistas e treinamento de técnicos especializados e desenvolver programas de prevenção e detecção do câncer em suas diversas áreas de incidência.

\section{Secretaria da Administração}

- formulação e execução da política de assistência médica ao servidor (IAMSPE)

\section{Secretaria de Obras e Saneamento:}

- planejar, promover e coordenar a aplicação das diretrizes governamentais nos assuntos referentes a: Saneamento...

- ações e planos integrados com vistas ao abastecimento e controle de qualidade da água distribuída às populações, ao destino final dos esgotos domésticos e despejos industriais e à melhoria das condições sanitárias das comunidades;

- programação do DAEE, participação societária SABESP, estudos e pesquisas hidrográficas, Saneamento Geral - FAE.

\section{Secretaria de Estado de Governo:}

- desenvolver atividades de ensino, treinamento, aperfeiçoamento e pesquisa na área de medicina e saúde, bem como de assistência médicohospitalar;

- realizar estudos, pesquisas e experiências em hematologia e hemoterapia e promover a formação de técnicos para o desenvolvimento de trabalhos nesse setor.

\section{- 75 - Saúde \\ HC São Paulo e HC Ribeirão}

Fundação Hemocentro de São Paulo, que atua em harmonia com o Programa Nacional de Sangue e Hemoderivados

Pró-Sangue

(d) O orçamento da Secretaria da Saúde reflete, de início, a estrutura vigente à época da promulgação da lei do orçamento. Posteriormente, por decreto, e em decorrência da reforma administrativa da Secretaria, foram estabelecidas novas unidades detentoras de recursos e executoras do orçamento, isto é, unidades orçamentárias e de despesas (Decreto $\mathrm{n}$. 26693 , de $2 / 2 / 87$. Dispõe sobre transferência de dotações orçamentárias e dá outras providências e, com base no artigo 89, da Lei $9717,30 / 1 / 67$, altera o orçamento aprovado pela Lei no 5403/86, na parte da Secretaria da Saúde).

A estrutura do sistema orçamentário-financeiro da Secretaria de Estado da Saúde, em decorrência da reforma da pasta (Decreto no 26774 de 18, publicado no D.O. de 19/04/87, que dispõe sobre organização da Secretaria da Saúde e dá providências correlatas) foi baixada pelo Decreto n. 26803, de 24, publicado no D.O. de $25 / 2 / 87$, conforme Tabela.

(e) Dada a mudança da Administração Montoro para a Administração Quércia, são esperadas transferências de subordinação e vinculação de órgãos na estrutura do Poder Executivo. Na área da Secretaria da Saúde, são esperadas importantes mudanças de vinculação, tais como as das autarquias Hospitais de Clínicas de São Paulo e Ribeirão Preto e, possivelmente, a de outra autarquia, o Instituto de Assitência Médica ao Servidor Público do Estado.

Será interessante acompanhar as mudanças, pois elas trarão, obrigatoriamente, também mudanças no orçamento público, com base no antigo 89 da Lei n. 9717/67, que dá competência do Governador do Es-

\begin{tabular}{|c|c|c|c|c|c|c|c|c|c|c|c|}
\hline \multirow[b]{2}{*}{ UNIDADES ORÇAMENTÁRIAS } & \multicolumn{11}{|c|}{ UNIDADES DE DESPESA } \\
\hline & $\begin{array}{c}\text { Gabinete } \\
\text { e } \\
\text { Asses- } \\
\text { sorias }\end{array}$ & $\begin{array}{l}\text { Órgãos } \\
\text { de apoio } \\
\text { e } \\
\text { recursos }\end{array}$ & FESIMA & $\begin{array}{l}\text { D.M.S. } \\
\text { CE. }\end{array}$ & C.V.S. & DP II & ERSAs & $\begin{array}{l}\text { Unidades } \\
\text { Inte- } \\
\text { gradas }\end{array}$ & $\begin{array}{l}\text { Hospitais } \\
\text { e Con- } \\
\text { juntos } \\
\text { Hospi- } \\
\text { talares }\end{array}$ & $\begin{array}{l}\text { Institutos } \\
\quad \text { de } \\
\text { Pesquisa }\end{array}$ & Total \\
\hline $\begin{array}{l}\text { 1. Adminstração Superior da } \\
\text { Secretaria e da Sede }\end{array}$ & 1 & 3 & 1 & 1 & 1 & 1 & & & 1 & & 9 \\
\hline 2. Coordenação de Regiões de Saúde 1 & $i$ & 1 & & & & & 15 & & & & 17 \\
\hline 3. Coordenação de Regiões de Saúde 2 & 1 & & & & & & 12 & 1 & 3 & & 17 \\
\hline 4. Coordenação de Regiões de Saúde 3 & 1 & & & & & & 11 & & 4 & & 16 \\
\hline 5. Coordenação de Regiões de Saúde 4 & 1 & & & & & & 15 & & & & 16 \\
\hline $\begin{array}{l}\text { 6. Coordenação de Regiões de Saúde } 5 \\
\text { 7. Coordenacão dos Institutos de }\end{array}$ & 1 & & & & & & 9 & & 4 & & 14 \\
\hline Pesquisa & 1 & & & & & & & & & 5 & 6 \\
\hline Administração Indireta: & & & & & & & & & & & \\
\hline $\begin{array}{l}\text { 8. Fundação do Remédio Popular } \\
\text { 9. Fundação Oncocentro de São Paulo } \\
\text { 10. Superintendência de Cont. Endemias }\end{array}$ & & & & & & & & & & & \\
\hline Totais & 7 & 4 & 1 & 1 & 1 & 1 & 62 & 1 & 12 & 5 & 95 \\
\hline
\end{tabular}


tado para efetuar reformas administrativas e transferir os respectivos recursos orçamentários.

(f) Os orçamentos da Secretaria de Estado da Saúde tiveram, no período de 1983 a 1987, os valores apresentados a seguir.

(g) Estas notas deverão ser complementadas com os dados obtidos da fixação de dotações pelas novas unidades da Secretaria de Estado da Saúde.
Comparativo da despesa da Secretaria da Saúde 1983 - 1987

Total do

Secr. Saude Estado c/ ICM \%

97.920.444 2.847.437.684 3,44

$\begin{array}{lll}312.533 .794 & 8.959 .520 .941 & 3,49\end{array}$

$\begin{array}{lll}1.364 .355 .061 & 35.871 .785 .359 & 3,80\end{array}$

1984

1985

1986 (prevista) $4.140 .214 .131 \quad 88.183 .584 .253 \quad 4,69$

1987 (prevista) $6.076 .733 .061 \quad 132.128 .069 .135 * 4,60$

Recebido para publicação em 7/4/1987 